\title{
Performance of Students in Number System Conversion using the Simplified Theorem and the Conventional Method
}

\author{
Jennifer Bagulaya-Abogaa \\ Associate Professor, College of Computer Studies \\ Eastern Samar State University, Borongan City, Philippines
}

\begin{abstract}
One development needs that the researcher would like to address is the result of the improvement of academic performance of students in the study of number systems using the simplified theorem. The researcher devised simplified theorem in converting number systems. In the College of Computer Studies of ESSU, one of the problems encountered by the student is the difficulty in manipulating number systems because of the complicated conventional method of solving and converting different number systems.

The researcher utilized descriptive-experimental method. The descriptive method described the academic performance of the students using tables and data recording. Experimental method was utilized in the study. Pairing of respondents was done to ensure the two groups are on the same performance level. One group was taught in conventional method of number systems conversion while the other group was taught in simplified method. Achievement exam was administered to both groups. The instrument was validated by the other number systems Professors to check the inconsistency and difficulty of the item questionnaire. An internal consistency test was done using the Cronbanch Alpha coefficient to test the reliability of the exam. Test items were deleted or revised depending on the recommendations of the number systems Professors and the obtained Cronbanch Alpha coefficient. Inferential statistics of t-test was used in determining the significant differences of the mean scores obtained within the group and between groups in terms of their level of performance in number system conversion.
\end{abstract}

The academic performance of respondents in number system conversion using simplified theorem is excellent with the mean score of 42.73 , while the those who used conventional method the mean score of achievement exam is 36.73. The performance percentage of the experimental group using simplified theorem is $85.47 \%$, and the control group using the conventional method of number system convention, the percentage of performance is $73.47 \%$, hence the percentage gained of the simplified theorem is $12 \%$. There is a significant difference in the performance of the respondents in simplified theorem and in conventional method in number systems conversion, in which the t-test computed is 3.893 , greater than the $\mathrm{t}$-test value of 2.704 at standard error of 0.005 .

\section{General Terms}

Academic Performance, Conversion, Conventional Method Decimal, Number System, Simplified Theorem.

\section{Keywords}

Architecture, Binary, Cronbanch, Discrete, Hexadecimal, Likert, Octal, IP or Internet Protocol.

\section{INTRODUCTION}

Numbers found on computer are represented in 0 s and $1 \mathrm{~s}$ or bits, from binary digits. These numbers are identified from their bases and it can be found in wide variety in the study of computers. Application of number systems is an integral components in different subjects such as Discrete Structures, Discrete Mathematics, Logic Circuits, Computer Systems Organization, Computer Systems Architecture and in Computer Networks.

Number systems are categorized into four: Binary, Octal, Hexadecimal and the most common is the Decimal number systems. These number systems can be converted from one category to another depending on application requirements. For example in computer networking, a student may have difficulty learning the IPV4 and IPV6 concept if the student doesn't know how to convert IP address in decimal form into IP address that is expressed in hexadecimal form. Khan (2013) stated, digital computer represents all kinds of data and information in the binary system. Thus, the study of number systems conversion should be given utmost attention.

One development needs that the researcher would like to address is the result of the improvement of academic performance of students in the study of number systems using the simplified theorem. The researcher devised simplified theorem in converting number systems. In the College of Computer Studies of ESSU, one of the problems encountered by the student is the difficulty in manipulating number systems because of the complicated conventional method of solving and converting different number systems.

\section{OBJECTIVES}

The study aimed to (1) determine the academic performance of second year Computer Science and Information Technology students in number systems conversion for SY 2016-2017; (2) determine the achievement scores of the respondents in number systems conversion assessment test using the simplified and conventional method; (3)determine the significant difference in the performance of the respondents in simplified and conventional method in number systems conversion; and (4) determine the percentage gained in the 
achievement scores of the students in number systems conversion using simplified theorem.

\section{RELATED LITERATURE}

Logic circuits are used to generate and transmit $1 \mathrm{~s}$ and $0 \mathrm{~s}$ to compute and convey information. This two-valued number system is called binary. There are many advantages of using a binary system; however, the human brain has been taught to count, label, and measure using the decimal number system. The decimal number system contains 10 unique symbols $(0-9)$ commonly referred to as the Arabic numerals. Each of these symbols is assigned a relative magnitude to the other symbols. For example, 0 is less than 1,1 is less than 2 , etc. It is often conjectured that the 10 -symbol number system that the humans use is due to the availability of the ten fingers (or digits) to visualize counting up to 10 . Regardless, his brains are trained to think of the real world in terms of a decimal system. In order to bridge the gap between the way, his brains think (decimal) and how he build the computers (binary), he need to understand the basics of number systems. This includes the formal definition of a positional number system and how it can be extended to accommodate any arbitrarily large (or small) value. This also includes how to convert between different number systems that contain different numbers of symbols. The study of decimal and binary is obvious as they represent how brains interpret the physical world (decimal) and how computers work (binary). Hexadecimal is studied because it is a useful means to represent large sets of binary values using a manageable number of symbols. Octal is rarely used but is studied as an example of how the formalization of the number systems can be applied to all systems regardless of the number of symbols they contain (LeMeres, B.J., 2017).

Weibull (2013) stated, computers perform all of their operations using the binary, or base 2, number system. All program code and data are stored and manipulated in binary form. Calculations are performed using binary arithmetic. Each digit in a binary number is known as a bit (for binary digit) and can have only one of two values, 0 or 1 . Bits are commonly stored and manipulated in groups of 8 (known as a byte), 16 (usually known as a halfword), 32 (a word), or 64 bits (a doubleword). Sometimes other groupings are used. The number of bits used in calculations affects the accuracy and size limitations of numbers manipulated by the computer. And, in fact, in some programming languages, the number of bits used can actually be specified by the programmer in declaration statements. In the programming language Java, for example, the programmer can declare a signed integer variable to be short (16 bits), int (32 bits), or long (64 bits) depending on the anticipated size of the number being used and the required accuracy in calculations.

\section{METHODS AND MATERIALS 4.1 Research Design}

The researcher utilized descriptive-experimental method The descriptive method described the academic performance of the students using tables and data recording. Experimental method was utilized in the study. Pairing of respondents was done to ensure the two groups are on the same performance level. One group was taught in conventional method of number systems conversion while the other group was taught in simplified method. Achievement exam was administered to both groups.
There was a 2-week time span completes the experimental study. At the end of the experimental period, same achievement test was administered to the two groups of Subjects.

\subsection{Instrument}

Research instrument was designed by the researcher covering the different competencies in number systems conversion. A 25 times-two item multiple choice type of exam was administered to the respondents.

\section{Achievement Test in Number System Conversion}

\section{Student}

Number Course/Sec Date:

Direction. Read the instruction carefully, and encircle the letter for every correct answer.

( 2 points each, resulting a total of 50 points).

Test I. Convert the following decimal numbers (base 10) to their binary (base 2) equivalents. You should not need a calculator.

1. $17=$
a. 10001
b. 11001

c. 00111 d. 10011

2. $24=$
a. 10001
b. 11000
c. 00111
d. 10011

3. $99=$
a. 1010001
b. 0011001
c. 1100011
d. 1110011

4. $115=$
a. 1110001
b. 1011001
c. 1000111
d. 1110011
$\begin{array}{ll}\text { a. } 10001111 & \text { b. } 11111001\end{array}$

c.10100111 d. 11110011

5. $143=$

Test II. Convert each of the following hexadecimal numbers to their binary equivalents.

1. $99=$
a. 10011001
b. 11111001
c. 11000111
d. 10110011

2. $\mathrm{F} 3=$
a. 10110001
b. 11110011
c. 00000111
d. 10010011

3. $\mathrm{DD}=$
a. 10001001
b. 1100111
c. 11011101
d. 10011101

4. $\mathrm{CF}=$
a. 10010001
b. 11001110
c. 00111000
d. 11001111

5. $60=$
a. 1100000
b. 1101001
c. 0110111
d. 1010011

Test III. Convert each of the following octal numbers to their decimal equivalents.
1. $25=$
a. 21
b. 34
c. 61
d. 31
2. $251=$ 

a. 216
b. 169
c. 179
d. 189

3. $403=$
a. 249
b. 269
c. 259
d. 279

4. $672=$
a. 421
b. 456
c. 498
d. 442

5. $75=$

$\begin{array}{ll}\text { a. } 61 & \text { b. } 63 \\ \text { c. } 67 & \text { d. } 69\end{array}$

Test IV. Convert the following decimal numbers (base 10) to their hexadecimal (base 16) equivalents. You should not need a calculator.

1. $189=$
a. BD
b. AE
c. $\mathrm{BC}$
d. 1D

2. $80=$
a. $5 \mathrm{~A}$
b. 50
c. 61
d. $6 \mathrm{~F}$

$\begin{array}{ll}\text { a. A2 } & \text { b. B2 } \\ \text { c. D2 } & \text { d. C2 }\end{array}$
a.B2
d. $\mathrm{C} 2$
c. A0
b. F2
a. 101
d. B0
c. $1 \mathrm{E} 1$
b. $1 \mathrm{~F} 1$

3. $210=$

4. $176=$

5. $257=$

Test IV. Convert the following octal numbers (base 8 ) to their hexadecimal (base 16) equivalents. You should not need a calculator.

$\begin{array}{ll}\text { 1. } 27= & \\ \text { a. } 17 & \text { b. } 18 \\ \text { c. } 21 & \text { d. } 29 \\ \text { 2. } 702= & \\ \text { a. } 1 \mathrm{~F} 2 & \text { b. } 1 \mathrm{C} 2 \\ \text { c. } 1 \mathrm{~B} 4 & \text { d. } 1 \mathrm{~A} 2 \\ \text { 3. } 562= & \\ \text { a. } 170 & \text { b. } 182 \\ \text { c. } 172 & \text { d. } 190 \\ \text { 4. } 54= & \text { b. } 2 \mathrm{~B} \\ \text { a. } 17 & \text { d. } 2 \mathrm{C} \\ \text { c. } 21 & \\ \text { 5. } 71= & \text { b. } 40 \\ \text { a. } 39 & \text { d. } 4 \mathrm{~B}\end{array}$

\subsection{Validation of Instrument}

The instrument was validated by the other number systems Professors to check the inconsistency and difficulty of the item questionnaire. An internal consistency test was done using the Cronbanch Alpha coefficient to test the reliability of the exam. Test items were deleted or revised depending on the recommendations of the number systems Professors and the obtained Cronbanch Alpha coefficient. If the Cronbanch Alpha coefficient is lower than 0.7, the test item will undergo series of revision until the cronbanch alpha coefficient becomes higher than 0.7 .
Table 1. Table of Likert Scale Question in Cronbanch Alpha

\begin{tabular}{|l|l|}
\hline Cronbanch Alpha & Consistency \\
\hline $\boldsymbol{\alpha} \geq \mathbf{0 . 9}$ & Excellent \\
\hline $0.9>\alpha \geq 0.8$ & Good \\
\hline $0.8>\alpha \geq 0.7$ & Acceptable \\
\hline $0.7>\alpha \geq 0.6$ & Questionable \\
\hline $0.6>\alpha \geq 0$. & Poor \\
\hline $0.5>\alpha$ & Unacceptable \\
\hline
\end{tabular}

Table 2. Table of Computation of Cronbanch Alpha

\begin{tabular}{|l|l|l|}
\hline Description & Variable & $\begin{array}{l}\text { Computed } \\
\text { Value }\end{array}$ \\
\hline Total Questions & $\mathrm{k}$ & 25 \\
\hline $\begin{array}{l}\text { Summation of } \\
\text { Variance }\end{array}$ & Evar & 3.26 \\
\hline $\begin{array}{l}\text { Average } \\
\text { Variance }\end{array}$ & Var & 14.44 \\
\hline $\begin{array}{l}\text { Cronbanch } \\
\text { Alpha }\end{array}$ & $\boldsymbol{\alpha}$ & $\mathbf{0 . 8 1}$ \\
\hline
\end{tabular}

Since the value of cronbach alpha is 0.81 (GOOD), the handmade achievement test was consistent.

\subsection{Respondents of the Study}

The respondents are the second year BSIT and BSCS students who were enrolled in College of Computer Studies, Eastern Samar State University for the SY 20162017. Respondents grouped into strata based on their academic performance in their College Algebra Subject. Grouping of respondents was done to ensure that high performing students, average and below average performing students are well represented. Total enumeration of respondents was used in the study.

\subsection{Statistical Tool}

Inferential statistics of t-test was used in determining the significant differences of the mean scores obtained within the group and between groups in terms of their level of performance in number system conversion. Comparing the significant differences of the mean scores obtained by the control group and the experimental group in the post-test, the t-test for independent samples was used. The percentage gained in the performance of the two groups was obtained to determine if the simplified approach is more effective method in teaching the number systems conversion.

\section{RESULT}

Table 3. Result of the Academic Performance of the Experiment in Simplified Theorem versus the Conventional Method @ df=58, t-value $=2.704$, and standard error $=0.005$.

\begin{tabular}{|l|l|l|}
\hline $\begin{array}{l}\text { Items used } \\
\text { in t-test } \\
\text { computation }\end{array}$ & $\begin{array}{l}\text { Simplified } \\
\text { Theorem } \\
\text { (Experimental } \\
\text { Group) }\end{array}$ & $\begin{array}{l}\text { Conventional } \\
\text { Method } \\
\text { (Control } \\
\text { Group) }\end{array}$ \\
\hline Mean $(\mathrm{x})$ & 42.73 & 36.73 \\
\hline $\begin{array}{l}\text { Square Sum } \\
\text { of Mean } \\
\left(\sum \mathrm{x}^{2}\right)\end{array}$ & 1643524 & 1214404 \\
\hline $\begin{array}{l}\% \text { of } \\
\text { Performance }\end{array}$ & 85.47 & 73.47 \\
\hline $\begin{array}{l}\text { Standard } \\
\text { Deviation }\end{array}$ & 1307.87 & 987.87 \\
\hline
\end{tabular}




\begin{tabular}{|l|c|}
\hline$(\mathrm{SD})$ & 12 \\
\hline$\%$ Gained & 3.893 \\
\hline $\begin{array}{l}\text { Computed t- } \\
\text { value }\end{array}$ & \\
\hline
\end{tabular}

The academic performance of respondents in number system conversion using simplified theorem is excellent with the mean score of 42.73 , while the those who used conventional method the mean score of achievement exam is 36.73 . The performance percentage of the experimental group using simplified theorem is $85.47 \%$, and the control group using the conventional method of number system convention, the percentage of performance is $73.47 \%$, hence the percentage gained of the simplified theorem is $12 \%$. There is a significant difference in the performance of the respondents in simplified theorem and in conventional method in number systems conversion, in which the t-test computed is 3.893 , greater than the t-test value of 2.704 at standard error of 0.005 .

\section{CONCLUSION}

Counting in bases other than 10 is essentially similar to the accustomed way of counting. Each digit place represents a count of a group of digits from the next less significant digit place. Conversion of number bases in which one base is an integer power of the other may be performed by recognizing that multiple digit places in the smaller base represent a single-digit place in the larger.

Simplified theorem must be implemented to all courses in Discrete Structures, Discrete Mathematics, Computer Systems Organization, Computer Systems Architecture, Computer Networks, and other course contents about number system conversion. It is important to note that number systems usually represent different mathematical meaning. Computations can easily be made by switching the right circuits and makes great model of arithmetic calculation for a computer.

\section{RECOMMENDATIONS}

Come-up a model-to-patent instructional theorem. Fractional and mixed numbers must be handled in the simplified theorem conversion, hence the integer and fractional parts must be treated independently of each other.

\section{REFERENCES}

[1] Bagulaya-Abogaa, Jennifer (2017), "Simplified Theorem in Number System Conversion", IJCA Volume 160-No3, February 2017, ISSN 0975-8887.

[2] Jaris, Janet. 2015. Instructional Evaluation System Template, Glade 2015-2015. Florida, USA.Khan Jhawad. 2013. Number System in Computer.

[3] Killian, Jason. 2012. Numbers Systems: An Introduction to Binary, Hexadecimal, and more.

[4] Demodharana V.S., ACCA. 2013. Innovative Method of Teaching. University of Arizona.

[5] [5] Hyttel, Hans. 2013. "What is the most powerful innovative idea/technique/principle ever used in mathematical proof?" Clark University.

[6] LeMeres, B.J. 2017. Introduction to Logic Circuits and Logic Design with VHDL. ISBN 973-3-31934194-1.

[7] Applying Gardner's Theory of Multiple Intelligence to Mathematics .2015.

[8] Gardner, H. 1991. The unschooled mind. New York.

[9] Weibull, Nikolai. 2013. An Historical Survey of Number Systems. pdf file. 